\title{
BMJ Open Probability of receiving a high cumulative radiation dose and primary clinical indication of CT examinations: a 5-year observational cohort study
}

\author{
Cécile R L P N Jeukens (D) , ${ }^{1}$ Hub Boere, ${ }^{1}$ Bart A J M Wagemans, ${ }^{1}$ \\ Patty J Nelemans, ${ }^{2}$ Estelle C Nijssen, ${ }^{1,3}$ Rebecca Smith-Bindman, ${ }^{4,5}$ \\ Joachim E Wildberger, ${ }^{1,3}$ Anna M Sailer ${ }^{1,6}$
}

To cite: Jeukens CRLPN, Boere $\mathrm{H}$, Wagemans BAJM, et al. Probability of receiving a high cumulative radiation dose and primary clinical indication of CT examinations: a 5 -year observational cohort study. BMJ Open 2021;11:e041883. doi:10.1136/ bmjopen-2020-041883

- Prepublication history for this paper is available online. To view these files, please visit the journal online (http://dx.doi org/10.1136/bmjopen-2020041883).

Received 19 June 2020 Revised 15 December 2020 Accepted 29 December 2020

Check for updates

(C) Author(s) (or their employer(s)) 2021. Re-use permitted under CC BY-NC. No commercial re-use. See rights and permissions. Published by BMJ.

For numbered affiliations see end of article.

Correspondence to Dr Cécile R L P N Jeukens; cecile.jeukens@mumc.nl

\section{ABSTRACT}

Objective High radiation exposure is a concern because of the association with cancer. The objective was to determine the probability of receiving a high radiation dose from CT (from one or more examinations within a 5-year period) and to assess the clinical context by evaluating clinical indications in the high-dose patient group.

Design Observational cohort study. Effective radiation dose received from one or more CT examinations within a predefined 5 -year calendar period was assessed for each patient.

Setting Hospital setting.

Participants All patients undergoing a diagnostic CT examination between July 2013 and July 2018 at the Maastricht University Medical Center.

Primary and secondary outcome measures The primary outcome was the probability of receiving a high effective dose, defined as $\geq 100 \mathrm{mSv}$, from one or more CT examinations within 5 years as derived from a timeto-event analysis. Secondary outcomes were the clinical indication for the initial scan of patients receiving a high effective dose.

Results 100672 CT examinations were performed among 49978 patients including 482 (1\%) who received a high radiation dose. The estimated probability of a high effective dose from a single examination is low $(0.002 \%(95 \% \mathrm{Cl}$ $0.00 \%$ to $0.01 \%))$. The 4.5 -year probability of receiving a high cumulative effective dose was $1.9 \%(95 \% \mathrm{Cl} 1.6 \%$ to $2.2 \%)$ for women and $1.5 \%(95 \% \mathrm{Cl} 1.3 \%$ to $1.7 \%)$ for men. The probability was highest in age categories between 51 and 74 years. A total of 2711 (5.5\%) of patients underwent more than six $\mathrm{CT}$ examinations, and the probability of receiving a high effective dose was $16 \%$. Among patients who received a high effective dose, most indications (80\%) were oncology related.

Conclusions The probability of receiving a high radiation dose from CT examinations is small but not negligible. In the majority (80\%) of high effective dose receiving patients, the indication for the initial CT scan was oncology related.

\section{INTRODUCTION}

In the 1970s, the development of CT paved the way for advanced diagnostic imaging.
Strengths and limitations of this study

- 100672 CT examinations performed between July 2013 and July 2018 at the Maastricht University Medical Center among 49978 unique patients were evaluated to estimate the probability of receiving a high dose $(\geq 100 \mathrm{mSv})$ from one or more CT examinations.

- Effective doses were calculated for each CT examination separately using a Monte Carlo module allowing to incorporate examination specific scanner settings.

- A time-to-event analysis was performed which accounts for differences in follow-up period between patients and provides a graph that visualises the increase in probability of receiving a high effective dose over time.

- The clinical indication for the initial scan of 482 high-dose receiving patients was extracted from medical records.

- The analysis was restricted to CT examinations performed at a single centre serving as a community hospital but also a tertiary medical centre, which may limit the ability to make generalisations.

Improvements in technology over time has further increased the use of CT, including the introduction of CT perfusion studies, four-dimensional imaging, dual-energy CT imaging and high-speed CT-angio whole body imaging. ${ }^{1}$ This increasing clinical value of CT imaging has resulted in an increase in the number of CT examinations over the last decade..$^{2-5}$ As many diseases and health conditions persist over time, there is also a potential increase in the number of examinations a patient will undergo in his or her lifetime due to monitoring. A drawback of CT imaging is the use of ionising radiation, which for high exposure levels may incur a risk of cancer from as early as $2-5$ years following imaging 
(leukaemia) to a persisting elevated risk that may last many decades (solid cancers). ${ }^{67}$

The risk of cancer associated with radiation exposure levels similar to those used for medical imaging is conventionally assessed using the linear no-threshold model. ${ }^{689}$ In this model, even the smallest radiation exposure level is considered to pose a risk, as extensive epidemiological data suggest effective doses in the range of $10-50 \mathrm{mSv}$ are carcinogenic. ${ }^{6}{ }^{10}$ Conversely, there remain organisations that question the risks associated with these exposures levels. Some organisations, such as the Health Physics Society and the American Association of Physicists in Medicine, ${ }^{11}{ }^{12}$ suggest that cancer risks are small or nonexistent with exposure levels below $100 \mathrm{mSv}$. However, effective doses of $100 \mathrm{mSv}$ and above are consistently considered carcinogenic, with numerous efforts made to reduce the number of individuals exposed to these high effective doses.

In an effort to reduce radiation doses and the associated risks, CT vendors have developed technical solutions including dose modulation and iterative reconstruction methods. As a result, dose reductions have been achieved for some procedures, such as routine chest or abdominal CT where a single phase is obtained. However, technical developments permitting faster scans and use of multiphase studies have also led to imaging that results in higher effective doses. In actual practice, while effective dose reduction has been possible over time, it has often been relinquished in favour of higher effective doses that lead to improved image quality. Furthermore, patients are often imaged repeatedly over time and may be receiving a high cumulative effective dose from multiple CT examinations. There is paucity of information in European settings on the percentage of patients undergoing CT examinations who accumulate high effective doses from recurrent CT examinations and clinical settings in which patients are likely to receive such high effective dose.
On the topic of high effective dose prevalence or subsequent clinical settings for the exams, some answers can be found in literature, ${ }^{13-18}$ none of which originate from our country. Furthermore, the incidence range of patients receiving high cumulative effective doses as reported in literature is wide: from $0 \%$ to $15 \%$ depending on study design and follow-up period. For some oncology patients with shortened life expectancy, cumulative effective doses may be considered of less importance since low 5-year survival implies low risk of radiation-induced malignancies. However, a recent study by Rehani $e t a l^{19}$ found that $14.3 \%$ of the group of patients that received high effective doses $(>100 \mathrm{mSv})$ for non-malignant diagnoses were relatively young ( $<40$ years).

To fill the gap in clinical literature on the topic, this observational study was conducted to determine the probability of receiving a high cumulative effective dose $(\geq 100 \mathrm{mSv})$ from one or more CT examinations and to assess the primary clinical indication for imaging of high effective dose-receiving patients.

\section{METHODS}

All CT examinations (diagnostic and CT-guided interventions) performed at Maastricht University Medical Center between 1 July 2013 and 1 July 2018 were included, and follow-up was assessed through 31 December 2019. This centre is primarily a tertiary university hospital while also serving as a community hospital. State-of-the-art equipment, advanced protocolling and dose quality assurance are the standard. ${ }^{20-23}$ The CT scanners included in this study are given in table 1. Follow-up was enabled by a single identification number for each patient.

\section{Data collection}

Radimetrics dose management software (Radimetrics Enterprise Platform, Bayer Healthcare, Berlin,

\begin{tabular}{|c|c|c|c|}
\hline & Type of CT scanner & Data collection period & $\%$ of CT examinations \\
\hline CT1 & $\begin{array}{l}\text { 16-slice scanner } \\
\text { (Somatom Sensation 16, Siemens } \\
\text { Healthineers, Forchheim, Germany) }\end{array}$ & 1 July 2013-14 August 2015 & 12.9 \\
\hline CT2 & $\begin{array}{l}\text { 64-slice scanner } \\
\text { (Brilliance CT 64, Philips Healthcare, Best, } \\
\text { The Netherlands) }\end{array}$ & 1 July 2013-9 January 2017 & 21.5 \\
\hline CT3 & $\begin{array}{l}\text { Second-generation dual source scanner } \\
\text { (Somatom Definition Flash, Siemens } \\
\text { Healthineers, Forchheim, Germany) }\end{array}$ & 1 July 2013-1 July 2018 & 37.9 \\
\hline CT4 & $\begin{array}{l}\text { Third-generation dual source scanner } \\
\text { (Somatom Force, Siemens Healthineers, } \\
\text { Forchheim, Germany) }\end{array}$ & 9 September 2015-1 July 2018 & 19.9 \\
\hline
\end{tabular}

CT1 and CT2 were taken out of service and CT4 and CT5 were newly installed during the inclusion period. 
Germany), was used to collect age (at the time of the first examination), sex, date and effective dose of each CT examination. All data were exported to an Excel format file (Microsoft Office Professional Plus 2010, Microsoft Corporation, Redmond, USA) for further analysis.

\section{Effective dose calculation}

Effective dose was used to quantify radiation dose for each examination. Effective dose is the sum of the organ doses multiplied by tissue weighting factors, which depend on radio sensitivity of each organ but not on age or sex. ${ }^{8}$ It is a useful measure as it reflects both the total amount of radiation emitted from the scanner and the future cancer risk associated with those exposures. Thus, the effective dose is a whole body surrogate measure related to the radiation detriment. The unit of effective dose is the sievert, which equals 1 joule per $\mathrm{kg}(1 \mathrm{~Sv}=1 \mathrm{~J} / \mathrm{kg})$. In diagnostic imaging, effective doses are usually in the millisievert $(\mathrm{mSv})$ range.

Effective doses were calculated using the Monte Carlobased module embedded in the dose management software. ${ }^{24}$ To accommodate for patient variations in length and weight, the module incorporates phantom models including 17 different sizes and three pregnant versions. After mapping the CT examination onto the phantom model most closely matching patient characteristics, the effective dose is calculated including incorporation of specific scanner settings. ${ }^{24}$ Exams with an effective dose of $100 \mathrm{mSv}$ or greater were considered high dose. Patients who received a cumulative effective dose of $100 \mathrm{mSv}$ or greater over the 5 years of the study were considered to have a high dose.

\section{Statistical analysis}

The primary analysis estimates the probability of receiving a high cumulative effective dose with a single exam or within the 5-year study period after the initial CT scan. All CT examinations performed on one patient were counted irrespective of indication or examination type. The cumulative effective dose, total observation period and number of CT examinations were calculated for each patient using a custom software script written in Python (Python V.3.4.4, Python Software Foundation, www.python.org). Among patients who received a high cumulative radiation dose at any one time during the study period, the clinical indication for the first CT scan was determined. For these high-dose patients, electronic medical records were individually reviewed with respect to the primary indication for imaging during the follow-up period ending on 31 December 2019.

Nominal and categorical variables are reported as absolute numbers and percentages. Continuous variables are reported as a mean with SDs (if normally distributed), or as a median with IQRs or range (for skewed distributions).

Time-to-event (Kaplan-Meier) analyses were performed to estimate the probability of having the event of interest: a high cumulative effective dose. Follow-up of a patient started at the date of the first CT examination within the 5-year inclusion period (between 1 July 2013 and 1 July 2018). For the primary analysis of probability of receiving a high effective dose, the follow-up ended on the date of which a high cumulative effective dose $(\geq 100 \mathrm{mSv})$ was reached or observations were censored at the end of the inclusion period (1 July 2018). The number of CT examinations recorded was equal to the number of CT examinations received during the follow-up period. The estimates of probability of receiving a high effective dose were calculated including 95\% CIs for the total population and for subgroups according to sex, age and number of CT examinations. Differences between groups were tested using the log rank test. All statistical analyses were performed using SPSS (IBM SPSS Statistics; V.25) and Stata (Survival Analysis, Statacorp, V.13). $\mathrm{P}<0.05$ was considered statistically significant.

\section{Medical ethics approval}

The local medical ethics committee approved the study and waived the requirement to obtain informed consent (METC 14-4-158).

\section{Patient and public involvement}

There was no formal involvement of patients or members of the public in developing the research questions, design and execution of the study, or interpretation of the results. There are no specific plans to disseminate the results to study patients beyond the usual channels of providing patient information in our hospital.

\section{RESULTS}

In total, 104428 CT examinations were performed within the inclusion period (103294 diagnostic CT examinations and 1134 CT-guided interventions; figure 1). A total of 3756 CT examinations (3.6\%) were excluded because effective dose data were unavailable. These excluded CT examinations were mostly $(77 \%)$ extremity CT scans (ie, of peripheral body structures such as the hand and joints such as the knee). The remaining 100672 CT examinations were all included in the analysis (46,710 CT examinations in women and 53962 in men).

The 100672 included CT examinations were done in a total of 49978 unique patients (23918 women and 26060 men). Median age was 62 (range $0-103$ ) years for women and 62 (range 0-102) years for men. A total of 2130 $(4.3 \%)$ patients were $<18$ years old (median 11 , range $0-17.9)$. The distribution of the number of CT examinations per patient is shown in table 2: median (IQR) number of CT examinations per patient was 1 (1-2), the maximum number of CT examinations per patient was 29. The majority of patients, $n=39499$ (79\%), received one to two CT examinations within the study period. A percentage of 4.7 received 6-10 CT examinations and $0.8 \%$ received $\geq 11 \mathrm{CT}$ examinations within the study period.

\section{Probability of receiving a high (cumulative) effective dose}

The distribution of effective doses received in a single examination was highly skewed (figure 2). Only one 


$$
\begin{aligned}
& 104,428 \text { CT-examinations at MUMC+ } \\
& \text { between July } 1^{\text {st }} 2013 \text { and July } 1^{\text {st }} 2018
\end{aligned}
$$

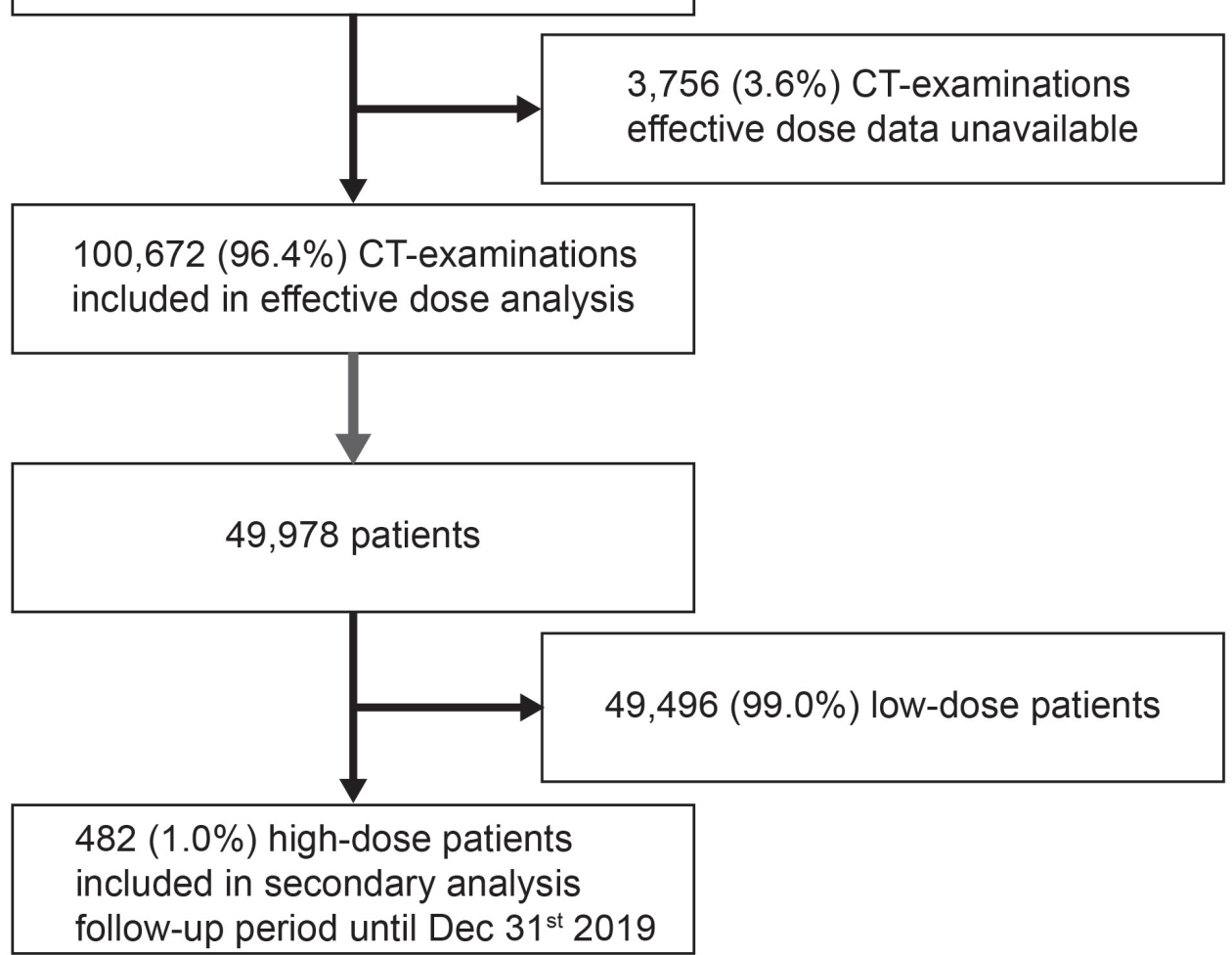

Figure 1 Screening and inclusion profile. MUMC+, Maastricht University Medical Centre+.

patient received a high effective dose during a single CT exam, which translates to a probability of $0.002 \%(95 \%$ CI $0.00 \%$ to $0.01 \%$ ).

Kaplan-Meier curves are shown in figure 3, which visualise the probability of receiving a high cumulative effective dose over time according to sex, age and total number of CT examinations. The Kaplan-Meier plots are presented along with the 'numbers at risk' below each graph. These numbers indicate how many patients were still in the cohort at that time point. Only a small number of patients had a follow-up period exceeding 4.5 years; therefore, cumulative probabilities at 4.5 (not 5) years

Table 2 Distribution of the number of CT examinations per patient in the 5-year study period

\begin{tabular}{|cc}
\hline \multirow{2}{*}{$\begin{array}{l}\text { Number of } \mathbf{C T} \text { examinations } \\
\text { per patient }\end{array}$} & Number of patients \\
\cline { 2 - 2 } & No. (\%) \\
\hline 2 & $30577(61.2)$ \\
\hline 3 & $8922(17.9)$ \\
\hline 4 & $4032(8.1)$ \\
\hline 5 & $2308(4.6)$ \\
\hline $6-10$ & $1428(2.9)$ \\
$\geq 11$ & $2336(4.7)$ \\
\hline Total & $375(0.8)$ \\
\hline
\end{tabular}

after the first CT examination are presented. The median follow-up period (from the date of the first CT examination) was 2.7 years (range 1 day to 5 years).

The probability of receiving a high cumulative effective dose shows a gradual linear increase over time and differed between the categories of sex (figure 3A) and age (figure $3 \mathrm{~B}$ ) and number of $\mathrm{CT}$ examinations received (figure 3C).

The 4.5-year probability of receiving a high cumulative effective dose was $1.9 \%$ (95\% CI $1.6 \%$ to $2.2 \%$ ) for women and $1.5 \%$ (95\% CI $1.3 \%$ to $1.7 \%$ ) for men; $2.5 \%$ for ages $51-64$ years (95\% CI $2.1 \%$ to $2.9 \%), 2.4 \%$ for ages $65-74$ years (95\% CI $2.0 \%$ to $2.9 \%$ ), $1.1 \%$ for ages $18-50$ years (95\% CI: $0.9 \%$ to $1.4 \%$; $\mathrm{p} \leq 0.05)$ and $0 \%$ for ages $<18$ years; $0.01 \%$ for patients with $1-2$ CT examinations $(95 \%$ CI $0.00 \%$ to $0.03 \%) ; 16 \%$ for patients with 6-10 CT examinations (95\% CI $14 \%$ to $18 \%$ ); and $32 \%$ for patients with 11 or more CT examinations (95\% CI $26 \%$ to $39 \%$ ).

\section{Baseline characteristics and primary clinical indications for} imaging of patients receiving high effective dose

Baseline characteristics of high-dose patients are given in table 3. A total of 482 patients received a high effective dose during the study period. Median age was 63 years (range 20-89). The majority of these patients $(52.9 \%)$ received 6-10 CT examinations during the study period. The median follow-up period of high-dose patients was 4.2 years (range 12 days- 6.5 years). 

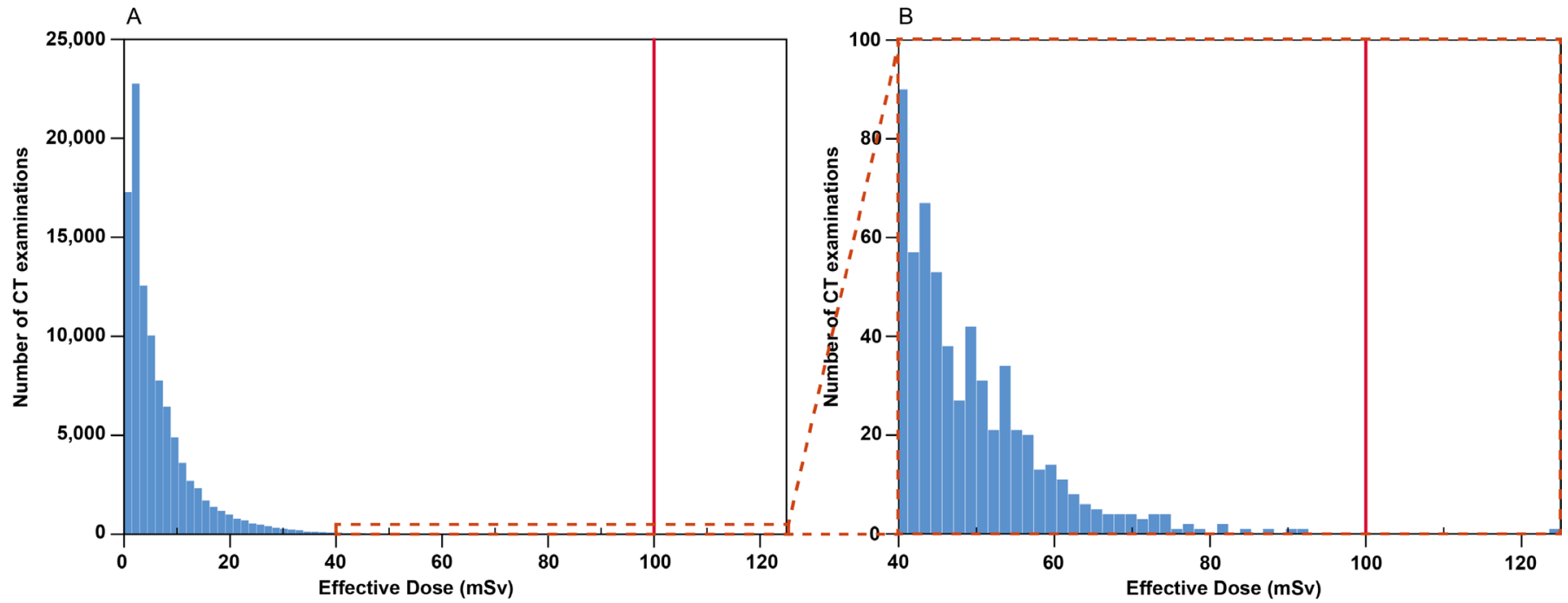

Figure 2 (A) Histogram of effective doses of 100672 CT examinations. (B) Enlargement of the histogram to visualise the number of examinations with effective doses $>40 \mathrm{mSv}$.

Primary clinical indications for CT examinations in patients receiving high effective doses are given in table 4 . The majority of indications $(80 \%)$ were related to evaluation or follow-up of a malignancy (wide variety of malignancies, predominantly breast cancer, urological and gastrointestinal malignancies), $8 \%$ to vascular disease (predominantly aortic aneurysm and dissection) and 8\% to non-malignant abdominal disease (predominantly pancreatitis and complicated colitis).

\section{DISCUSSION}

This study included 100672 CT examinations performed among 49978 patients at a single tertiary referral centre within a 5-year calendar period. The probability of receiving a high effective dose $(\geq 100 \mathrm{mSv})$ in a single CT exam was low $(0.002 \%$ (95\% CI $0.00 \%$ to $0.01 \%)$ ). Nearly $40 \%$ of patients received multiple CT examinations, and the probability of receiving a high cumulative effective dose after 4.5 years was $1.9 \%$ for women and $1.5 \%$ for men. The probability of receiving a high effective dose from one to two CT examinations was $0.01 \%$ versus $16 \%$ from 6 to 10 CT examinations and $32 \%$ from $\geq 11 \mathrm{CT}$ examinations.

Four hundred and eighty-two patients were identified as receiving a high cumulative effective dose, with a median age of 63 years (range 20-89). More than half of these patients underwent 6-10 CT examinations within the study period. As could be expected, almost all highdose receiving patients underwent more than one CT examination. This is in line with a recent study ${ }^{25}$ where of a cohort of 8952 patients receiving a high effective dose $(\geq 100 \mathrm{mSv})$, only 33 received this in a single day or single procedure, which were all CT-guided interventions. Eighty per cent of the CT examination referrals for high-dose patients were oncology related. The latter is similar to findings reported in the literature, ${ }^{1314}$ although Rehani $e t$ $a l^{19}$ found $90 \%$ oncology-related referrals. At the centre of the current study, continuous effort is undertaken to optimise dose and image quality. ${ }^{22}{ }^{23}$ While radiation doses at this centre are similar to those in Switzerland and Germany, they were found to be lower than radiation doses in the USA. ${ }^{21}$

These findings support tracking radiation dose on an individual level. Of course, every exam involving ionising radiation should be properly justified. Patient radiation tracking might hypothetically lead to increased dose awareness among radiologists and referring physicians. In a time where use of CT imaging continues to increase, awareness of the cumulative radiation exposure and the accompanying potential health risk, in particular for younger patients, may lead to more careful and deliberate consideration and justified use of CT examinations.

In the current study, radiation exposure was quantified by calculating the effective dose using a Monte Carlo-based module embedded in the dose management software. The effective dose was introduced by the International Commission on Radiological Protection as a measure for exposure to moderate and low levels of radiation. ${ }^{8}$ Effective dose can be related to health detriment but was not primarily intended to monitor individual risks. For riskbenefit assessment, the recommended method is to estimate the absorbed organ doses. ${ }^{8}$

Previous studies have reported percentages of patients receiving high cumulative radiation doses due to diagnostic CT imaging. ${ }^{13-17}$ However, reported results are difficult to compare with the current study due to differences in study design, population, follow-up and effective dose estimation methods (where either typical effective doses per CT examination ${ }^{13-15}$ or estimated effective doses ${ }^{161726}$ were used). Also, a recent study by Rehani and Hauptman ${ }^{18}$ demonstrated up to a sixfold variation between countries in the estimated number of patients receiving high cumulative effective doses relative to the population of a country. Two population-based studies ${ }^{145}$ 


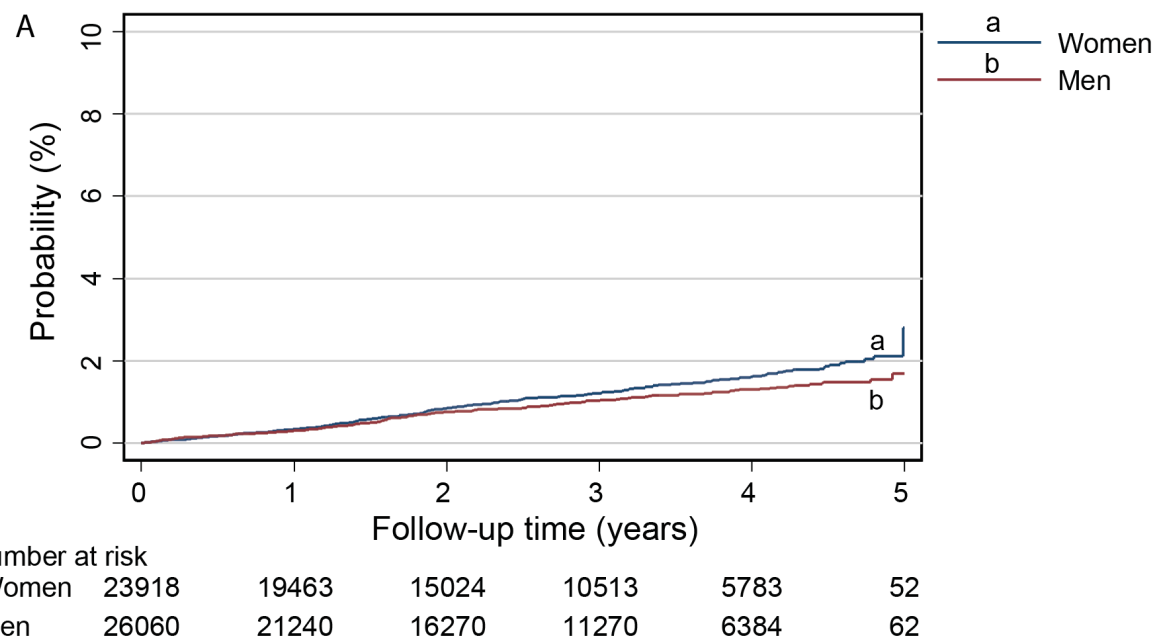

Number at risk
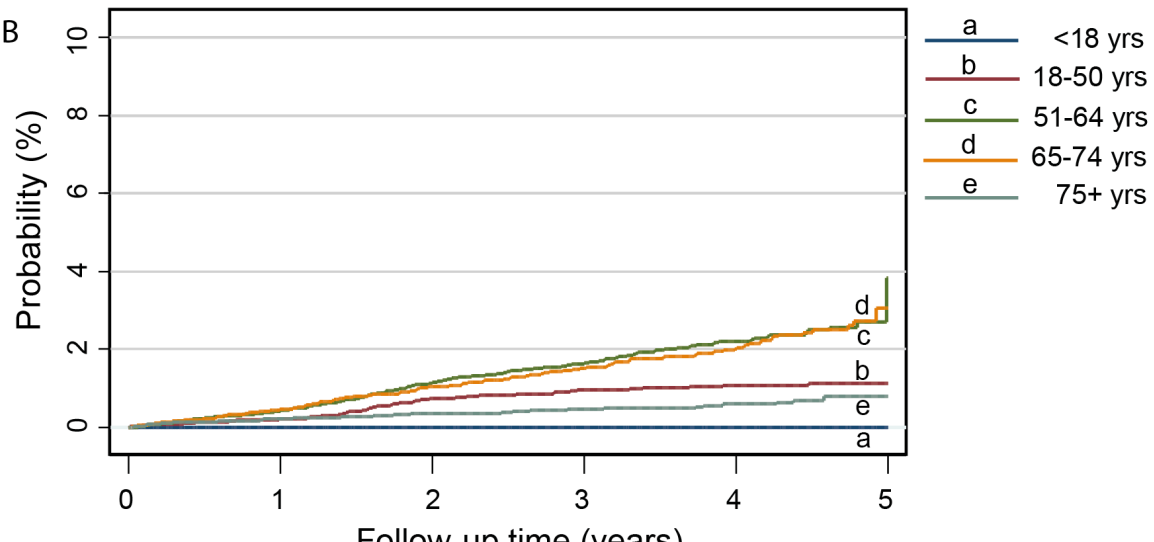

$\begin{array}{rcccccc}<18 \text { yrs } & 2130 & 1755 & 1313 & 892 & 475 & 2 \\ 18-50 \text { yrs } & 12023 & 9792 & 7546 & 5254 & 2907 & 23 \\ 51-64 \text { yrs } & 13688 & 11139 & 8547 & 5923 & 3390 & 29 \\ 65-74 \text { yrs } & 11309 & 9200 & 7056 & 4905 & 2795 & 35 \\ 75+\text { yrs } & 10828 & 8817 & 6832 & 4809 & 2600 & 25\end{array}$

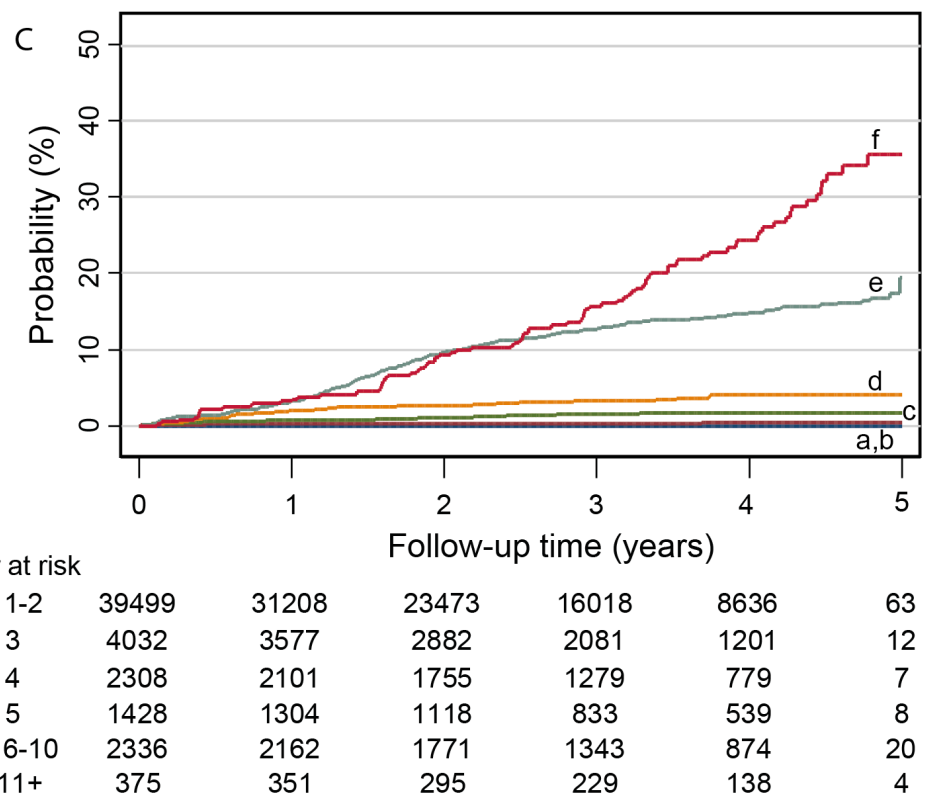

Figure 3 Kaplan-Meier curves that visualise the probability of receiving a cumulative effective dose of $\geq 100 \mathrm{mSv}$ over time by (A) sex, (B) age category and (C) number of CT examinations within the study period. The follow-up time starts at the first CT examination. 


\begin{tabular}{lr}
$\begin{array}{l}\text { Table } 3 \\
(\mathrm{n}=482)\end{array}$ & Baseline characteristics of high-dose patients \\
\hline Category & No. (\%) \\
\hline $\begin{array}{l}\text { Sex } \\
\text { Women }\end{array}$ & $256(53.1)$ \\
\hline Men & $226(46.9)$ \\
\hline Age (years) & \\
\hline$<18$ & $0(0.0)$ \\
\hline $18-50$ & $88(18.3)$ \\
\hline $51-64$ & $194(40.2)$ \\
\hline $65-74$ & $154(32.0)$ \\
\hline$\geq 75$ & $46(9.5)$ \\
\hline Number of CT examinations & \\
\hline $1-2$ & $2(0.4)$ \\
\hline 3 & $6(1.2)$ \\
\hline 4 & $19(3.9)$ \\
\hline 5 & $29(6.0)$ \\
\hline $6-10$ & $255(52.9)$ \\
\hline$\geq 11$ & $171(35.5)$ \\
\hline
\end{tabular}

used well-defined and large study populations living in specific areas of Spain (224751 people) ${ }^{14}$ and the USA (54447 adults). ${ }^{15}$ They reported analyses of the subgroups of inhabitants undergoing at least one CT examination in the study period. Reported estimates of the percentage of patients receiving a cumulative effective dose $>100 \mathrm{mSv}$ were $8.2 \%$ for a 12-year period in Spain and $1.9 \%$ for a 10 -year period in the USA. The authors of the latter study indicate that they likely underestimated cumulative effective doses and percentages because average effective dose estimates per CT examination were taken. This does not account for higher BMI patients receiving higher effective doses. Conversely, the Spanish study is likely an overestimation as exposure was extrapolated, assuming the same exposure rate for patients that could not be followed for 12 years.

A few hospital-based studies report percentages of patients reaching a cumulative effective dose $\geq 100 \mathrm{mSv}$ in patients referred for a CT examination. The highest percentage was reported by Sodickson $e t \mathrm{al}^{13}$ in a cohort of 31462 patients undergoing CT in a tertiary academic medical centre in the USA. Evaluation of all recorded CT exams over 22 years leading up to 2007 showed that $15 \%$ of patients received an effective dose $\geq 100 \mathrm{mSv}$. The percentage of patients receiving more than five CT examinations in this study is high $(33 \% / 22$ years $)$, which may explain the relatively high incidence of high-dose patients found. In a study by Rehani $e t a l,{ }^{16}$ in patients from four centres (three in USA and one in Central Europe), the percentage of patients receiving a high effective dose ranged from $0.64 \%$ to $3.4 \%$ (average $1.3 \%$ ) for a follow-up duration of 1-5 years. A survey yielding data from 20 countries $^{17}$ reported percentages ranging
Table 4 Clinical indication for imaging in high-dose patients $(n=482)$

\begin{tabular}{|c|c|}
\hline & Number of patients \\
\hline Malignancy & $\mathrm{n}=384(79.7 \%)$ \\
\hline Breast cancer & 75 \\
\hline Urologic malignancy & 63 \\
\hline Colon carcinoma & 53 \\
\hline Rectum carcinoma & 29 \\
\hline Melanoma & 28 \\
\hline Pancreatic carcinoma & 24 \\
\hline Lung cancer & 19 \\
\hline Gynaecological malignancy & 13 \\
\hline Hepatocellular carcinoma & 14 \\
\hline Lymphoma & 13 \\
\hline Sarcoma & 11 \\
\hline Cholangio-carcinoma & 11 \\
\hline Testis malignancy & 10 \\
\hline Neuroendocrine tumour & 7 \\
\hline Head and neck tumour & 7 \\
\hline $\begin{array}{l}\text { Gastrointestinal stromal } \\
\text { tumour }\end{array}$ & 4 \\
\hline Other: unknown primary & 3 \\
\hline $\begin{array}{l}\text { Non-malignant abdominal } \\
\text { disease }\end{array}$ & $\mathrm{n}=39(8.1 \%)$ \\
\hline Pancreatitis & 28 \\
\hline Colitis & 5 \\
\hline Kidney stones & 4 \\
\hline Liver lesion differentiation & 2 \\
\hline Vascular disease & $\mathrm{n}=37(7.7 \%)$ \\
\hline Aortic dissection & 16 \\
\hline Aortic aneurysm & 11 \\
\hline $\begin{array}{l}\text { Other peripheral artery } \\
\text { disease, vasculitis, heart valve } \\
\text { pathology and acute bleeding }\end{array}$ & 9 \\
\hline High energy trauma & $\mathrm{n}=9(1.9 \%)$ \\
\hline Other & $n=13(2.7 \%)$ \\
\hline Failed surgery & 9 \\
\hline Interstitial lung disease & 4 \\
\hline
\end{tabular}

from $0.0 \%$ to $5.0 \%$ with a follow-up duration ranging from 0.4 to 6.1 years. None of these hospital-based studies performed time-to-event (survival) analyses to account for differences in varying follow-up periods between patients, which might have led to bias. ${ }^{27} 28$

A strength of the current study is that effective doses were calculated for each CT examination separately using a Monte Carlo-based module. This is in line with previous research ${ }^{161719}$ and has the advantage of incorporating scanner-specific settings such as scan range rather than using generic literature-based effective dose values. Another strength of the current study is the 
Kaplan-Meier analysis, which accounts for differences in follow-up periods between patients and provides a graph that visualises the increase in probability of receiving a high effective dose over time. Finally, the current paper adds information on the European context to the mainly US-centric information in current literature. Studies by Smith-Bindman $e t$ al show that effective doses at US sites are generally higher than those at European sites. ${ }^{21}$

There are some limitations to our study. First, the analysis on cumulative effective dose was restricted to CT examinations that were performed at a single centre, which limits the ability to generalise. Maastricht University Medical Center serves as community hospital and a tertiary medical centre. The probability of receiving a high cumulative effctive dose for patients who are referred to a tertiary centre will strongly depend on efforts undertaken to optimise the use of state-of-the-art CT scanners with respect to dose and image quality. CT examinations performed at other centres were not included in the cumulative effective dose analysis, nor was radiation exposure due to other sources such as conventional X-ray, fluoroscopy and nuclear medicine. As a result, cumulative effective doses will tend to underestimate. A potential solution for this matter requires a unique registration of patients over time in a broad perspective. Dose-related data can be tracked based on a unique personal number like the BSN in the Netherlands. This will require political support on that matter on a national or even a European level. Second, a recent study ${ }^{29}$ has shown that the absorption of contrast medium can considerably increase the absorbed dose in contrast-uptaking organs. The Monte Carlo-based module embedded in the dose management software used to estimate the effective dose in the current study does not incorporate this effect and may underestimate effective dose in contrast to media CT examinations. Third, the time-to-event analysis could only partially account for differences in follow-up period between patients. In the primary analysis, censoring the observations of patients who died or were referred to another hospital before the end of the inclusion period was not possible, because this information was not available. As a result, the numbers at risk during follow-up are overestimated and the probability of receiving a high cumulative effective dose may have been underestimated. The aforementioned limitations result in underestimation of cumulative effective dose, and therefore results must be interpreted as being minimum probabilities, further underscoring the necessity of tracking radiation dose.

\section{CONCLUSIONS}

The probability of receiving a high cumulative effective dose $\geq 100 \mathrm{mSv}$ from CT examinations is small but not negligible and increases linearly with time. In the majority $(80 \%)$ of high-dose-receiving patients the indication for the initial CT scan was oncology related. These findings advocate the need for patient dose tracking to gain insight into individual cumulative radiation exposure and to increase awareness of the radiation exposure among radiologists and referring physicians.

\section{Author affiliations}

${ }^{1}$ Department of Radiology and Nuclear Medicine, Maastricht University Medical Centre+, Maastricht, The Netherlands

${ }^{2}$ Department of Epidemiology, Maastricht University, Maastricht, The Netherlands ${ }^{3}$ CARIM, School for Cardiovascular Diseases, Maastricht University Medical Center, Maastricht, The Netherlands

${ }^{4}$ Department of Radiology and Biomedical Imaging Epidemiology and Biostatistics, University of California San Francisco, San Francisco, California, USA

${ }^{5}$ Department of Obstetrics Gynecology and Reproductive Sciences, Philip R Lee Institute for Health Policy Studies, University of California, San Francisco, San

Francisco, USA

${ }^{6}$ Department of Radiology, Stanford University School of Medicine, Stanford, California, USA

Correction notice This article has been corrected since it was published. Affiliation 3 has been added to Joachim E Wildberger.

Contributors CRLPNJ, JW, PJN and AMS designed the study. CRLPNJ, HB, BAJMW and AMS collected the data. CRLPNJ, HB, PJN and AMS analysed the data. CRLPNJ, PJN, RSB, JW and AMS interpreted the data. CRLPNJ, ECN and AMS drafted the manuscript. All authors critically evaluated, revised and approved the manuscript. The corresponding author attests that all listed authors meet authorship criteria and that no others meeting the criteria have been omitted. CRLPNJ is the guarantor.

Funding The authors have not declared a specific grant for this research from any funding agency in the public, commercial or not-for-profit sectors.

Competing interests None declared.

Patient and public involvement Patients and/or the public were not involved in the design, or conduct, or reporting, or dissemination plans of this research.

Patient consent for publication Not required.

Provenance and peer review Not commissioned; externally peer reviewed.

Data availability statement Data are available on reasonable request. On request, the used Python code or anonymised raw data can be shared by contacting the corresponding author.

Open access This is an open access article distributed in accordance with the Creative Commons Attribution Non Commercial (CC BY-NC 4.0) license, which permits others to distribute, remix, adapt, build upon this work non-commercially, and license their derivative works on different terms, provided the original work is properly cited, appropriate credit is given, any changes made indicated, and the use is non-commercial. See: http://creativecommons.org/licenses/by-nc/4.0/.

ORCID iD

Cécile R L P N Jeukens http://orcid.org/0000-0003-1403-8301

\section{REFERENCES}

1 Liguori C, Frauenfelder G, Massaroni C. Emerging clinical applications of computed tomography. Med Devices 2015;8:265-78.

2 Brenner DJ, Hall EJ. Computed tomography--an increasing source of radiation exposure. N Engl J Med 2007;357:2277-84.

3 Mettler FA, Bhargavan M, Faulkner K, et al. Radiologic and nuclear medicine studies in the United States and worldwide: frequency, radiation dose, and comparison with other radiation sources--1950-2007. Radiology 2009;253:520-31.

4 Hricak $\mathrm{H}$, Brenner DJ, Adelstein SJ, et al. Managing radiation use in medical imaging: a multifaceted challenge. Radiology 2011;258:889-905.

5 Smith-Bindman R, Miglioretti DL, Johnson E, et al. Use of diagnostic imaging studies and associated radiation exposure for patients enrolled in large integrated health care systems, 1996-2010. JAMA 2012;307:2400-9.

6 Health Risks from Exposure to Low Levels of Ionizing Radiation: BEIR VII Phase 2. Board of radiation effects research division on earth and life sciences national Research Council of the National academies. Washington, DC: The National Academies Press, 2006.

7 United Nations Scientific Committee on the Effects of Atomic Radiation. Sources, effects and risks of ionizing radiation Annex $F$ radiation carcinogenesis in man, 1988. 
8 The 2007 recommendations of the International Commission on radiological protection. ICRP publication 103. Ann ICRP 2007;37:1-332.

9 UNSCEAR. Sources and effects of ionizing radiation. United nations scientific Committee on the effects of atomic radiation (UNSCEAR. New York: United Nations publication, 2008.

10 Preston DL, Ron E, Tokuoka S, et al. Solid cancer incidence in atomic bomb survivors: 1958-1998. Radiat Res 2007;168:1-64.

11 HPS. Radiation risk in perspective: position paper of the health physics Society. Available: http://hps.org/documents/radiationrisk. pdf [Accessed 11 Dec 2020].

12 AAPM. AAPM position statement on radiation risks from medical imaging procedures. American association of physicists in medicine. Available: http://www.aapm.org/org/policies/details.asp?id=318\& type=PP\&current=true; [Accessed 11 Dec 2020].

13 Sodickson A, Baeyens PF, Andriole KP, et al. Recurrent CT, cumulative radiation exposure, and associated radiation-induced cancer risks from CT of adults. Radiology 2009;251:175-84.

14 Lumbreras B, Salinas JM, Gonzalez-Alvarez I. Cumulative exposure to ionising radiation from diagnostic imaging tests: a 12-year followup population-based analysis in Spain. BMJ Open 2019;9:e030905.

15 Stopsack KH, Cerhan JR. Cumulative doses of ionizing radiation from computed tomography: a population-based study. Mayo Clin Proc 2019;94:2011-21.

16 Rehani MM, Yang K, Melick ER, et al. Patients undergoing recurrent CT scans: assessing the magnitude. Eur Radiol 2020;30:1828-36.

17 Brambilla M, Vassileva J, Kuchcinska A, et al. Multinational data on cumulative radiation exposure of patients from recurrent radiological procedures: call for action. Eur Radiol 2020;30:2493-501.

18 Rehani MM, Hauptmann M. Estimates of the number of patients with high cumulative doses through recurrent CT exams in 35 OECD countries. Phys Med 2020;76:173-6.

19 Rehani MM, Melick ER, Alvi RM, et al. Patients undergoing recurrent CT exams: assessment of patients with non-malignant diseases, reasons for imaging and imaging appropriateness. Eur Radiol 2020;30:1839-46.
20 Boere H, Eijsvoogel NG, Sailer AM, et al. Implementation of sizedependent local diagnostic reference levels for CT angiography. AJR Am J Roentgenol 2018;210:W226-33.

21 Smith-Bindman R, Wang $\mathrm{Y}$, Chu P, et al. International variation in radiation dose for computed tomography examinations: prospective cohort study. BMJ 2019;364:k4931.

22 Hendriks BMF, Schnerr RS, Milanese G, et al. Computed tomography pulmonary angiography during pregnancy: radiation dose of commonly used protocols and the effect of scan length optimization. Korean J Radiol 2019;20:313-22.

23 Smith-Bindman R, Chu P, Wang Y, et al. Comparison of the effectiveness of single-component and multicomponent interventions for reducing radiation doses in patients undergoing computed tomography: a randomized clinical trial. JAMA Intern Med 2020;180:666-75.

24 Bayer HealthCare Medical Care. Radiation dose calculation in RadimetricsTM enterprise platform by Bayer. white paper RADINF-13-05968 Bayer healthcare, 2014.

25 Arellano RS, Yang K, Rehani MM. Analysis of patients receiving $\geq 100$ $\mathrm{mSv}$ during a computed tomography intervention. Eur Radiol 2020. doi:10.1007/s00330-020-07458-5. [Epub ahead of print: 12 Nov 2020]

26 Martin CJ, Harrison JD, Rehani MM. Effective dose from radiation exposure in medicine: past, present, and future. Phys Med 2020;79:87-92.

27 Singh R, Mukhopadhyay K. Survival analysis in clinical trials: basics and must know areas. Perspect Clin Res 2011;2:145-8.

28 Zee J, Xie SX. The Kaplan-Meier method for estimating and comparing proportions in a randomized controlled trial with Dropouts. Biostat Epidemiol 2018;2:23-33.

29 Perisinakis K, Tzedakis A, Spanakis K, et al. The effect of iodine uptake on radiation dose absorbed by patient tissues in contrast enhanced CT imaging: implications for CT dosimetry. Eur Radiol 2018;28:151-8. 